\title{
Surface-initiated growth of copper using isonicotinic acid-functionalized aluminum oxide surfaces
}

\author{
Cathren E. Gowenlock, Virginia Gomez, James D. McGettrick, \\ Enrico Andreoli, Andrew R. Barron
}

(C) The Author(s) 2016. This article is published with open access at Springerlink.com

\begin{abstract}
Isonicotinate self-assembled monolayers (SAM) were prepared on alumina surfaces (A) using isonicotinic acid ( $i \mathrm{NA})$. These functionalized layers (iNA-A) were used for the seeded growth of copper films (Cu-iNA-A) by hydrazine hydrate-initiated electroless deposition. The films were characterized by scanning electron microscopy (SEM), electron-dispersive X-ray spectroscopy, atomic force microscopy, Xray photoelectron spectroscopy, X-ray diffraction, and advancing contact angle measurements. The films are $\mathrm{Cu}^{0}$ but with surface oxidation, and show a faceted morphology, which is more textured $\left(R_{\mathrm{q}}=460 \pm 90\right.$ $\mathrm{nm})$ compared to the SAM $\left(R_{\mathrm{q}}=2.8 \pm 0.5 \mathrm{~nm}\right)$. In contrast, growth of copper films by $\mathrm{SnCl}_{2} / \mathrm{PdCl}_{2}$ catalyzed electroless deposition, using formaldehyde $\left(\mathrm{CH}_{2} \mathrm{O}\right)$ as the reducing agent, shows a nodular morphology on top of a relatively smooth surface. No copper films are observed in the absence of the isonicotinate SAM. The binding of $\mathrm{Cu}^{2+}$ to the $i \mathrm{NA}$ is proposed to facilitate reduction to $\mathrm{Cu}^{0}$ and create the seed for subsequent growth. The films show good adhesion to the functionalized surface.
\end{abstract}

C. E. Gowenlock, V. Gomez, E. Andreoli,

A. R. Barron $(\square)$

Energy Safety Research Institute (ESRI), College of

Engineering, Swansea University, Bay Campus, Swansea,

Wales SA1 8EN, UK

e-mail: a.r.barron@swansea.ac.uk; arb@rice.edu

\section{J. D. McGettrick}

SPECIFIC, Baglan Bay Innovation \& Knowledge Centre, College of Engineering, Swansea University, Baglan, Port Talbot, Wales SA12 7AX, UK

\section{A. R. Barron}

Department of Chemistry and Department of Materials Science and Nanoengineering, Rice University, Houston, TX 77005, USA
Keywords Copper, Isonicotinic acid, Aluminum oxide, Thin film, Electroless deposition

\section{Introduction}

As a thin film deposition method, electroless deposition (ELD) is relatively simple and less expensive, is performed at ambient or low temperature, and can be potentially selective. ${ }^{1,2}$ In comparison with electrochemical deposition, ELD occurs via chemically promoted reduction of metal ions without external current and is thus suitable for a wide range of substrates, including insulators. ELD has also found application in the coating of a range of nanoparticles. ${ }^{3,4}$ It is used in a wide range of applications to deposit copper including the preparation of chip interconnects. 5,6

Self-assembled monolayers (SAMs) with varying functionalities have been demonstrated to direct the assembly of inorganic thin films via ELD. ${ }^{7-9}$ The reason for this selective deposition is that the functionality of the SAM acts as an accelerator molecule to control crystal heterogeneous nucleation and growth. Amino groups, catechols, and thiols have all been used to seed metallic ELD copper growth on surfaces, ${ }^{10-12}$ and they can also be used to assist in electrochemical deposition. ${ }^{13}$ Pyridine and related derivatives represent one of the most common ligand types for copper, ${ }^{14-17}$ and we have used this in our work with copper-specific complexes. ${ }^{18-21}$ We have recently reported that isonicotinic acid (Fig. 1) functionalization of alumina nanoparticles allows for the highly stable binding of copper acetate $\left(\mathrm{Cu}_{2}\left(\mathrm{O}_{2} \mathrm{CMe}\right)_{4}\right),{ }^{22}$ and we have also shown that its derivatives allow for binding of metals to specific locations on nanoparticles. ${ }^{23}$ The use of the acid form allows for the covalent binding to the aluminum oxide surface, ${ }^{24-27}$ and thus we have investigated the ability of isonicotinic acid-functionalized alumina thin films to promote the ELD of copper with 


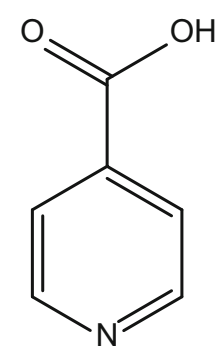

Fig. 1: Structure of isonicotinic acid

hydrazine as a reducing agent. In order to show the robustness of the method, formaldehyde with tin/palladium catalysis was used as an alternative reducing agent. These results are presented herein.

\section{Experimental}

\section{Materials and methods}

Isonicotinic acid ( $i \mathrm{NA}$ ), copper(II) sulfate pentahydrate $\left(\mathrm{CuSO}_{4} \cdot 5 \mathrm{H}_{2} \mathrm{O}\right)$, hydrazine hydrate $\left(\mathrm{N}_{2} \mathrm{H}_{4} \cdot \mathrm{H}_{2} \mathrm{O}\right)$, ethylenediaminetetraacetic acid (EDTA), formaldehyde solution (37 wt \%), tin(II) chloride $\left(\mathrm{SnCl}_{2}\right)$, and palladium(II) chloride $\left(\mathrm{PdCl}_{2}\right)$ were purchased from Sigma-Aldrich, Ltd. and used as received. Aluminacoated silicon wafers prepared by atomic layer deposition (ALD) were provided by Natcore Technology, Inc. (NTX.V).

The morphologies of the samples and their elemental composition were examined using scanning electron microscopy (SEM) and quantitative electron-dispersive X-ray (EDX) spectroscopy with a Hitachi Field Emission S-4800 SEM with an Inca electron-dispersive X-ray detector (Oxford Instruments, Abingdon, UK) for EDX experiments. The surfaces of the samples were studied by a JPK NanoWizard II Atomic Force Microscope (AFM) using noncontact cantilevers (RTESP, Bruker). Intermittent contact mode was used to take $20 \times 20 \mu \mathrm{m}$ images for each sample at a scan rate of $0.5-1 \mathrm{~Hz}$ and an image resolution of $512 \times 512$ pixels. The images were analyzed using JPK offline processing software. The mean roughness root-meansquare $\left(R_{\mathrm{q}}\right)$, averaged roughness $\left(R_{\mathrm{a}}\right)$, and the peak-tovalley roughness $\left(R_{\mathrm{t}}\right)$ were determined from the AFM scans for each sample.

X-ray photoelectron spectra (XPS) were recorded on a Kratos Axis Supra instrument (Kratos Analytical, Manchester, UK) using a monochromated Al-K ${ }_{\alpha}$ source. All spectra were recorded using a charge neutralizer to limit differential charging and subsequently calibrated to the main adventitious $\mathrm{C}_{x} \mathrm{H}_{y}$ carbon peak at a binding energy of $284.8 \mathrm{eV}$. Survey scans were recorded at a pass energy of $160 \mathrm{eV}$ and high-resolution data at a pass energy of $20 \mathrm{eV}$. Data were fitted using CASA XPS with Shirley backgrounds. X-ray diffraction (XRD) patterns were recorded on a Brüker D8 DISCOVER diffractometer in Bragg-Brentano geometry with a $\mathrm{Cu}-\mathrm{K}_{\alpha}$ X-ray source $(\lambda=0.15418 \mathrm{~nm})$ and analyzed using Match 2 software.

Advancing water contact angle measurements were made under ambient conditions using the sessile drop shape method. Contact angles were calculated using Drop Shape Analysis DSA1 software provided with the Kruss FM40 Easydrop goniometer (Kruss, Germany). Contact angles on three different regions of each sample were measured and averaged.

\section{Preparation of isonicotinic acid-functionalized alumina thin films}

Isonicotinic acid-functionalized alumina surfaces were prepared following a modification of the literature protocols. $^{27,28}$ The alumina-coated silicon wafer (100) substrates were immersed in an aqueous solution of isonicotinic acid $(0.2 \mathrm{M})$ and left for 6 days at $50^{\circ} \mathrm{C}$. Wafers were removed and rinsed sequentially with water $(5 \times 30 \mathrm{~mL})$, acetone $(1 \times 30 \mathrm{~mL})$, and benzene $(1 \times 30 \mathrm{~mL})$ to ensure the removal of any unreacted isonicotinic acid and then oven dried overnight at $80^{\circ} \mathrm{C}$.

\section{Copper ELD using hydrazine as the reducing agent}

Copper plating of alumina wafers by electroless deposition was carried out following an adaptation of a literature protocol. ${ }^{11} \mathrm{An}$ aqueous room-temperature solution $(40 \mathrm{~mL})$ of $\mathrm{CuSO}_{4} \cdot 5 \mathrm{H}_{2} \mathrm{O}(0.054 \mathrm{M})$ acted as a source of copper(II) ions, stabilized by chelation with EDTA $(0.034 \mathrm{M})$. Coupons $\left(20 \mathrm{~mm}^{2}\right)$ of pristine (unfunctionalized) alumina-coated silicon wafer (A) and isonicotinic acid-functionalized alumina wafer ( $i \mathrm{NA}$ A) were added to the solution prior to the addition of hydrazine hydrate solution $(1.3 \mathrm{~mL})$, which triggers the electroless deposition process. After completion of electroplating, the wafer pieces were removed from the solution, washed copiously with deionized water $(5 \times 30 \mathrm{~mL})$ and ethanol $(5 \times 30 \mathrm{~mL})$, and then oven dried overnight at $80^{\circ} \mathrm{C}$.

\section{Copper ELD using formaldehyde as the reducing agent}

Alumina wafers were also copper plated by an alternative electroless deposition process, using a traditional tin- and palladium-based activation process and formaldehyde solution. $^{29}$ A filter paper $(5 \mathrm{~cm}$ in diameter) was immersed in a sensitizer solution $(50 \mathrm{~mL})$ of $\mathrm{SnCl}_{2}(0.04 \mathrm{M})$ and $\mathrm{HCl}(0.5 \mathrm{M})$ for $1 \mathrm{~min}$, rinsed with deionized water, and then immersed in an activator solution $(50 \mathrm{~mL})$ of $\mathrm{PdCl}_{2}(1 \mathrm{mM})$ and $\mathrm{HCl}(0.05 \mathrm{M})$ for $1 \mathrm{~min}$. The filter paper was then rinsed with deionized water. An aqueous solution 
$(100 \mathrm{~mL})$ of $\mathrm{CuSO}_{4} \cdot 5 \mathrm{H}_{2} \mathrm{O}(0.04 \mathrm{M})$ and EDTA $(0.04 \mathrm{M})$ at $70^{\circ} \mathrm{C}$ was adjusted to $\mathrm{pH} 12$ with $\mathrm{NaOH}$, and coupons $\left(20 \mathrm{~mm}^{2}\right)$ of pristine (unfunctionalized) alumina-coated silicon wafer (A) and isonicotinic acidfunctionalized alumina wafer $(i \mathrm{NA}-\mathrm{A})$ were added to the solution. Formaldehyde solution (0.08 M) was added, followed by the palladium-treated filter paper. After completion of electroplating, the wafer pieces were removed from the solution, washed copiously with deionized water $(5 \times 30 \mathrm{~mL})$ and ethanol $(5 \times 30 \mathrm{~mL})$, and then oven dried overnight at $80^{\circ} \mathrm{C}$.

\section{Results and discussion}

Figure 2 shows a schematic diagram of the functionalization of alumina-coated $\mathrm{Si}$ wafer with isonicotinic acid ( $i \mathrm{NA})$ and the subsequent $\mathrm{Cu}$ ELD reaction. In order to determine the effects of the $i \mathrm{NA}$, unfunctionalized wafers were also exposed to the ELD solutions. Two ELD reactions were investigated using hydrazine (equation 1) or formaldehyde (equation 2) as the reducing agent. ${ }^{11,29}$ The latter reaction uses a tin- and palladium-based activation process.

$$
\begin{aligned}
\mathrm{CuSO}_{4} \cdot 5 \mathrm{H}_{2} \mathrm{O}+\mathrm{N}_{2} \mathrm{H}_{4} \rightarrow & \mathrm{Cu}+\mathrm{N}_{2}+\mathrm{H}_{2} \mathrm{SO}_{4} \\
& +5 \mathrm{H}_{2} \mathrm{O}
\end{aligned}
$$

$\mathrm{Cu}^{2+}+2 \mathrm{H}_{2} \mathrm{CO}+4 \mathrm{OH}^{-} \rightarrow 2 \mathrm{HCO}_{2}^{-}+2 \mathrm{H}_{2} \mathrm{O}+\mathrm{H}_{2}$

\section{Morphology}

The surface morphology of the alumina-coated wafers was examined using SEM prior to and after function- (a)
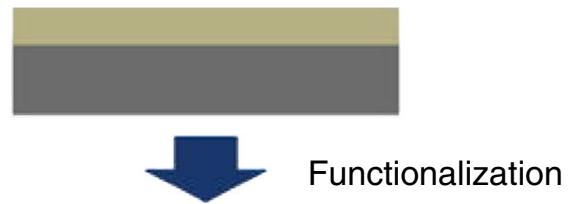

(b)
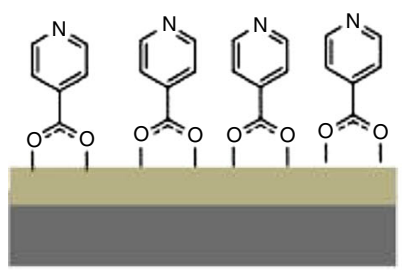

\section{Coordination of $\mathrm{Cu}^{2+}$}

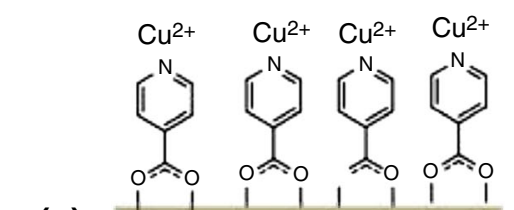

(c)

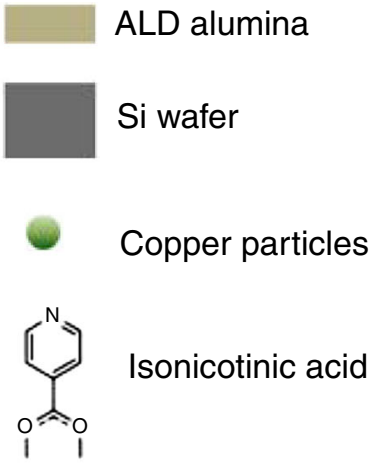

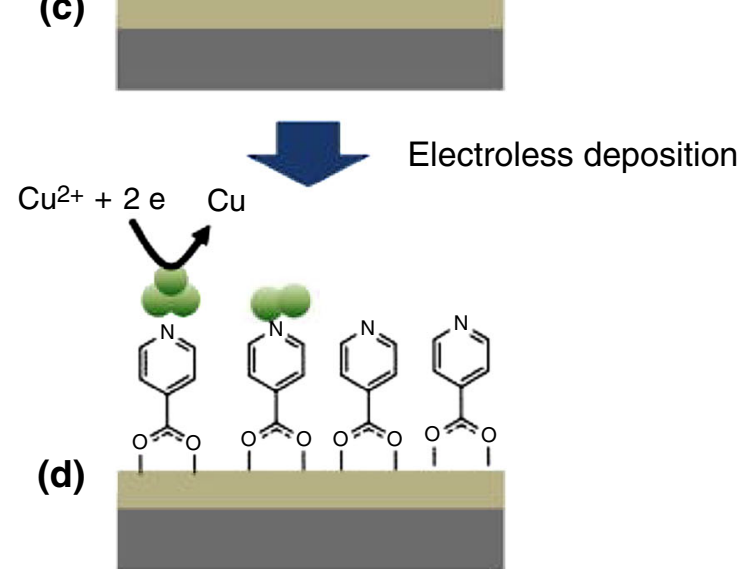

Fig. 2: Schematic illustration of the functionalization of alumina-coated Si wafer with isonicotinic acid and the subsequent electroless copper deposition reaction 

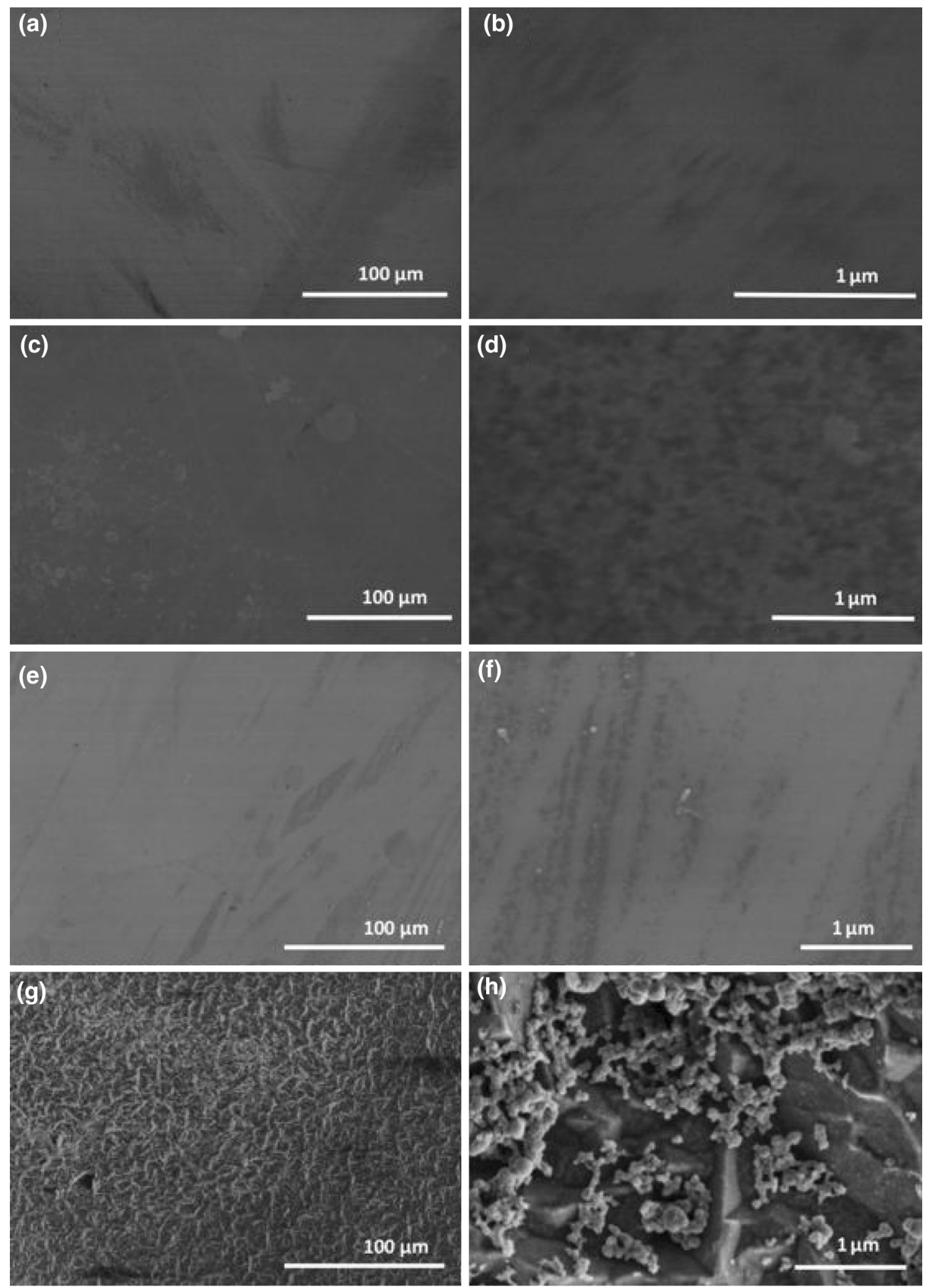

Fig. 3: SEM micrographs of untreated alumina-coated silicon wafer (a and b), iNA-functionalized alumina (c and d), hydrazine-activated Cu ELD on the untreated alumina (e and f), and hydrazine-activated Cu ELD on the iNA-functionalized alumina ( $g$ and $h$ ) 
(a)

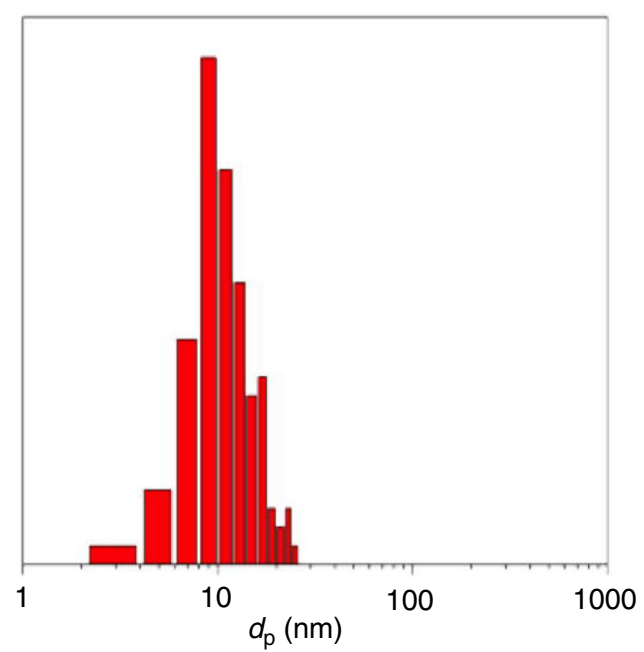

(b)

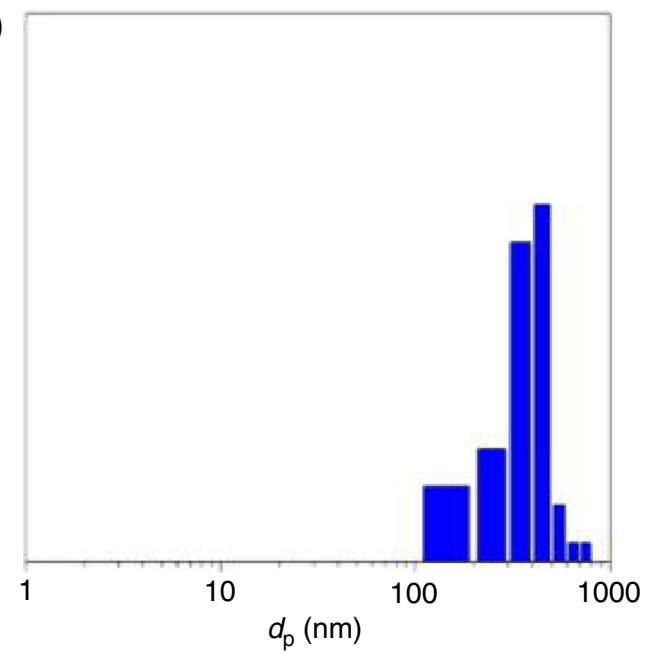

Fig. 4: Particle size distribution from SEM micrographs of Cu ELD on the INA-functionalized alumina activated with (a) hydrazine and (b) formaldehyde

alization, and after electroless deposition. Typical SEM micrographs (Figs. 3a and 3b) of the alumina-coated wafer (A) before functionalization show that the surface is relatively smooth. Figures $3 c$ and $3 d$ show that after functionalization with isonicotinic acid ( $i \mathrm{NA}$ A) this smoothness is retained. The slight change in texturing at higher magnification (Fig. 3d as compared to Fig. 3b) is typical of the SAM formation on atomic layer-deposited alumina, ${ }^{27}$ as a result of the solubilization (through NP formation) of some of the alumina. ${ }^{24}$ In the absence of $i$ NA functionalization, the hydrazineactivated ELD results in a surface (Figs. $3 \mathrm{e}$ and $3 \mathrm{f}$ ) that is similar to the untreated sample. However, there are some discernable features that are consistent with the presence of homogeneous nucleation (see below). In contrast, after ELD and washing, the isonicotinic acidfunctionalized wafer $(\mathrm{Cu}-i \mathrm{NA}-\mathrm{A})$ surface consisted of a highly textured uniform coating (Fig. 3g). The surface appears to be formed from interlocking crys-

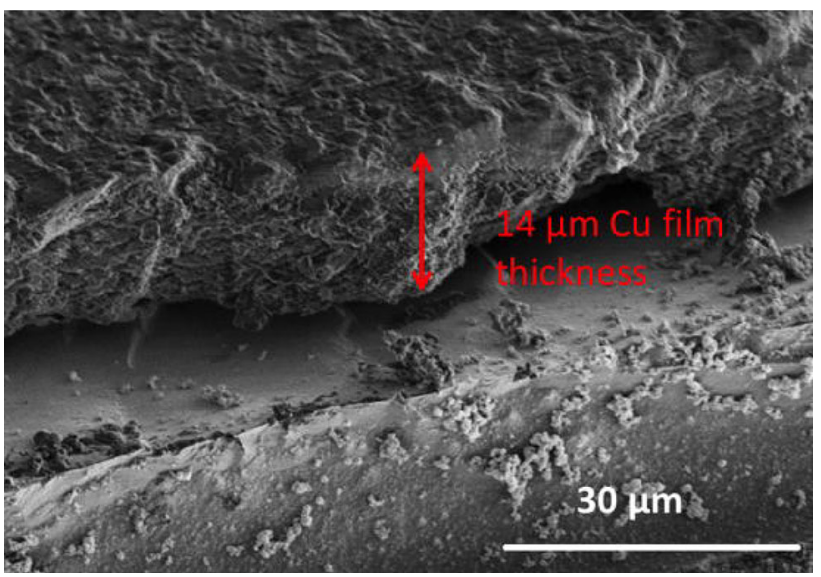

Fig. 5: SEM image of the cross section of the hydrazineactivated $\mathrm{Cu}$ ELD on the iNA-functionalized alumina wafer

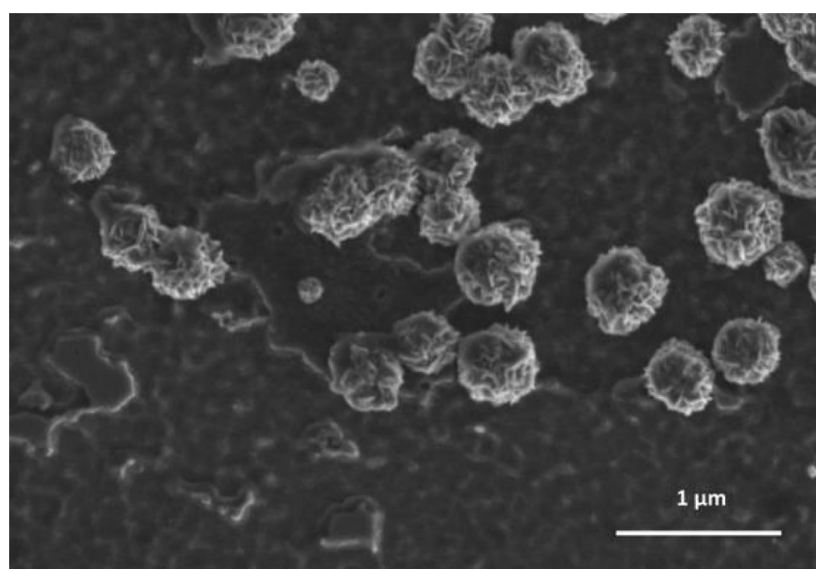

Fig. 6: SEM micrograph of formaldehyde-activated Cu ELD on the INA-functionalized alumina

talline facets, which is confirmed by AFM and XRD (see below). At higher magnification (Fig. 3h), it may be seen that the faceted surface is sparsely covered in small nodular growth. The size distribution of these particles $(12 \pm 4 \mathrm{~nm})$ is shown in Fig. 4a. A crosssectional SEM image (Fig. 5) shows a uniform $\mathrm{Cu}$ layer with uniform texture throughout the film.

The use of formaldehyde as the reducing agent results in a different texture to the $\mathrm{Cu}$ surface (Fig. 6). The major portion of the surface appears to be far less faceted than that with the hydrazine activation. As with the hydrazine-activated ELD, there are also nodular growths on the wafer surface (Fig. 6), but these are significantly larger $(150 \pm 30 \mathrm{~nm}$, see Fig. 4 b) and appear to grow out of the surface rather than be deposited from the solution.

AFM characterization of the different surfaces of the samples is shown in Fig. 7 and Table 1. Height measurements of the alumina-coated silicon wafer (A) revealed a relatively flat surface of around $0.1-2.0 \mathrm{~nm}$ 

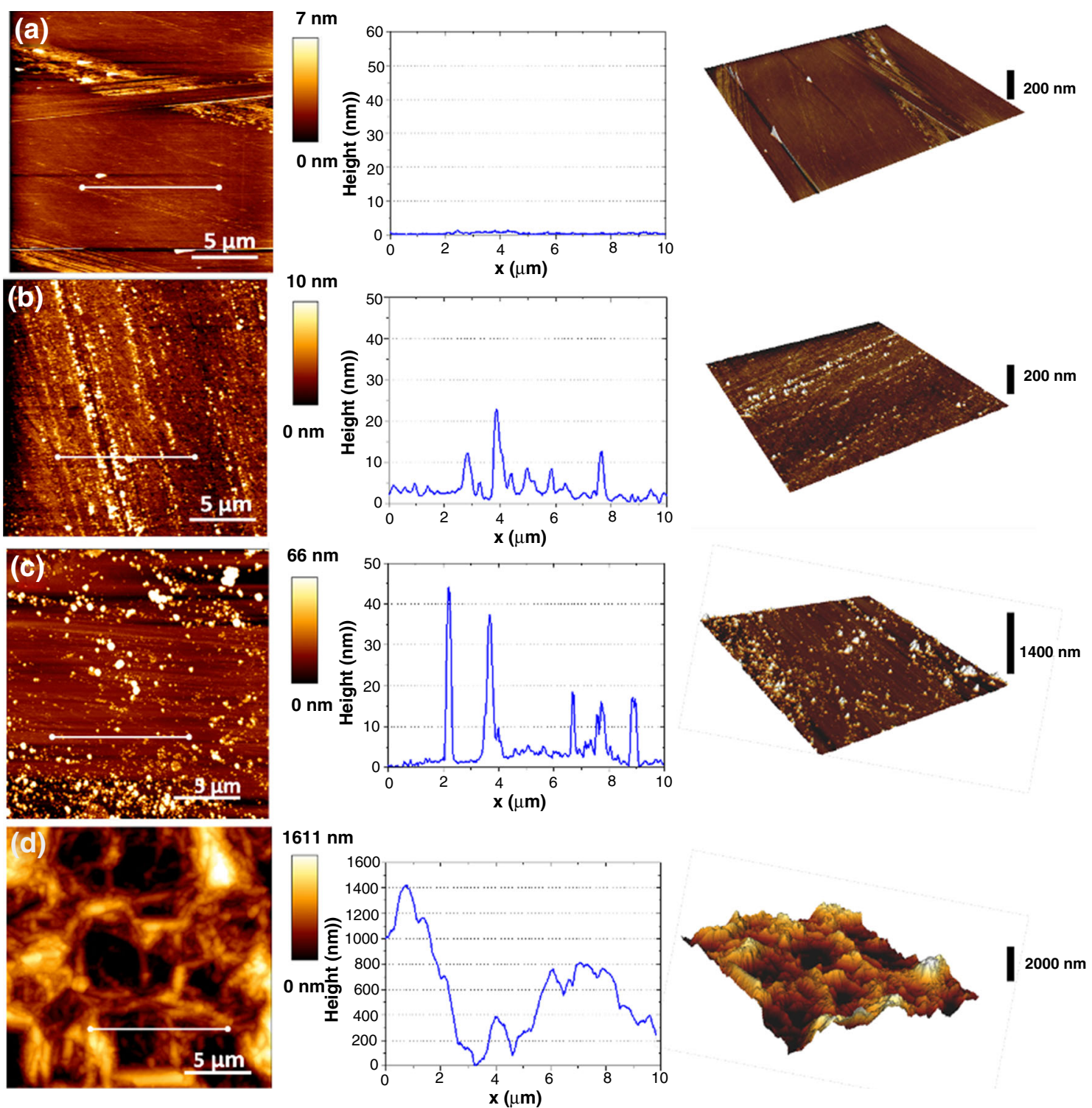

Fig. 7: AFM images, height profiles along the white line, and 3D projections of (a) alumina-coated silicon wafer (A), (b) isonicotinic acid-functionalized alumina (INA-A), (c) hydrazine-activated ELD Cu on the unfunctionalized wafer (Cu-A), and (d) hydrazine-activated ELD $\mathrm{Cu}$ on the isonicotinic acid-functionalized alumina (Cu-iNA-A). Images were obtained with a scan size of $20 \times 20 \mu \mathrm{m}$

Table 1: Values of the average roughness $\left(R_{\mathrm{a}}\right)$, mean roughness root-mean-square $\left(R_{\mathrm{q}}\right)$, and the peak-to-valley roughness $\left(R_{\mathrm{t}}\right)$ determined from the AFM scans

\begin{tabular}{lcrr} 
Sample & $R_{\mathrm{a}}(\mathrm{nm})$ & $R_{\mathrm{q}}(\mathrm{nm})$ & $R_{\mathrm{t}}(\mathrm{nm})$ \\
\hline A & $1.0 \pm 0.6$ & $3 \pm 3$ & $130 \pm 90$ \\
Cu-A & $8.9 \pm 0.9$ & $15 \pm 2$ & $280 \pm 65$ \\
NA-A & $1.4 \pm 0.1$ & $2.8 \pm 0.5$ & $130 \pm 10$ \\
Cu-NA-A & $360 \pm 57$ & $460 \pm 87$ & $3000 \pm 1500$
\end{tabular}

(Fig. 7a), which upon functionalization by isonicotinic acid becomes slightly rougher, i.e., $0.2-20 \mathrm{~nm}$ (Fig. 7b), but shows a similar $\mathrm{R}_{\mathrm{q}}$ value to that of the unfunctionalized sample (Table 1). The AFM image of the hydrazine-activated $\mathrm{Cu}$ ELD on the unfunctionalized alumina surface (Fig. 7c) is consistent with the presence of $10-40 \mathrm{~nm}$ particles sparsely distributed on the surface. These are the same range as observed 
scattered on the surface of $\mathrm{Cu}-i \mathrm{NA}-\mathrm{A}$ samples by SEM (Fig. 3h). However, these features are not observed in the AFM of the Cu-iNA-A samples (Fig. 7d) due to any such variation being swamped by the textured base layer of $\mathrm{Cu}$, as seen in the associated SEM.

The formation of the textured contiguous coating (irrespective of the reducing agent) can be rationalized by assuming that the $\mathrm{N}$ functionalization of $i \mathrm{NA}-$ SAMs forms complexes with $\mathrm{Cu}^{2+}$ from solution, a heterogenous nucleation reaction continuously takes place at the surface, and the as-formed nanocrystals are assembled to a contiguous film. Support for this proposal is the observation ${ }^{22}$ that $i \mathrm{NA}$-functionalized alumina nanoparticle ( $i \mathrm{NA}-\mathrm{NP})$ complex with copper acetate $(\mathrm{CuA})$ to form a stable conjugate $(\mathrm{CuA}-i \mathrm{NA}$ $\mathrm{NP}$ ). Thus, the $i \mathrm{NA}$ successfully directs $\mathrm{Cu}$ growth to the surface. The similarity in size of the particulate features in the hydrazine-activated $\mathrm{Cu}-i \mathrm{NA}-\mathrm{A}$ (Figs. 3 $\mathrm{h}$ and $4 \mathrm{a}$ ) to those in the $\mathrm{Cu}-\mathrm{A}$ (Fig. 7c) suggests that these features in the $\mathrm{Cu}-\mathrm{A}$ are dropped onto the surface from solution (possibly during removal of the sample from the reaction bath), rather than grown from the surface, and were subsequently not removed in the washing step.

\section{Surface chemical composition}

As expected from the ca. $1 \mu \mathrm{m}^{3}$ analysis volume of EDX, the spectra for the untreated and iNA-functionalized samples show predominantly the $\mathrm{Si}$ wafer substrate (Table 2) since the ALD alumina layer is ca. $500 \mathrm{~nm}$. EDX analysis of the hydrazine-activated $\mathrm{Cu} \mathrm{ELD}$ on the $i \mathrm{NA}$-functionalized alumina surface (Cu-iNA-A) shows the expected $\mathrm{Cu}$ and a decrease in both $\mathrm{Si}$ and $\mathrm{Al}$ as compared to the pre-ELD substrate ( $i$ NA-A), see Table 2 . In contrast, analysis after $\mathrm{Cu}$ ELD on the unfunctionalized alumina surface shows only a trace of $\mathrm{Cu}$ consistent with the SEM and AFM results.
Further evidence for the $\mathrm{Cu}$ deposition on the isonicotinic acid-functionalized alumina films was obtained from XPS (Table 3). As expected, there is a decrease in $\mathrm{Si}, \mathrm{Al}$, and $\mathrm{O}$ content with the formation of the $\mathrm{Cu}$ ELD on $i \mathrm{NA}-\mathrm{A}$. This is consistent with the SEM and AFM data. It is interesting to note that the $\mathrm{N}$ content increases after $\mathrm{Cu}$ deposition, although it would be expected to decrease given that the isonicotinic should be coated by the $\mathrm{Cu}$ (i.e., Fig. 2). However, we note that the sample prepared by $\mathrm{Cu}$ ELD on the unfunctionalized surface also contains nitrogen. The high-resolution $\mathrm{N}$ 1s peak for $\mathrm{Cu}-\mathrm{A}$ and $\mathrm{Cu}-i \mathrm{NA}-\mathrm{A}$ is shown in Fig. 8. The presence of $\mathrm{N}$ in the former is presumably a residue (or a side product) from the hydrazine reducing agent, ${ }^{30}$ which gives an almost identical binding energy to $\mathrm{N}$ in pyridine derivatives. ${ }^{31-34}$ Figure $8 \mathrm{~b}$ shows the high-resolution $\mathrm{Cu} 2 \mathrm{p}$ envelope where two photoelectron peaks $\left(\mathrm{Cu} 2 \mathrm{p}_{3 / 2}\right.$ and $\mathrm{Cu} 2 \mathrm{p}_{1 / 2}$ ) can be observed for both $\mathrm{Cu}-\mathrm{A}$ and $\mathrm{Cu}-i \mathrm{NA}-$ A samples. The presence of satellite features (designated by arrows) is usually related with the presence of $\mathrm{Cu}(\mathrm{II})$ oxide. $^{35}$

\section{Surface and structural properties}

The XRD patterns of the copper-plated pristine alumina $(\mathrm{Cu}-\mathrm{A})$ and the copper-plated isonicotinic acid-functionalized alumina (Cu-iNA-A) are shown in Fig. 9. The wafers comprise a ca. $500 \mathrm{~nm}$ layer of alumina formed on the silicon wafer by ALD, and as such, the XRD pattern is dominated by the pattern for [004] peak of the silicon wafer. As orientated Si wafers were used for all samples, in some cases peaks for the forbidden reflection [002] $\left(2 \theta=32.8^{\circ}\right)$ and other signals such as $2 \theta=61.7^{\circ}$ and $2 \theta=65.9^{\circ}$ caused either by instrumental artifacts ${ }^{36}$ in the oriented substrate or due to the "invisible" laser markings on the original $\mathrm{Si}$ wafer are observed. ${ }^{37}$ No peaks for the alumina are observed due to the thinness of the layer and its polycrystalline nature. However, a small peak consis-

Table 2: EDX analysis (atomic\%)

\begin{tabular}{lccccc} 
Sample & $\mathrm{Si}$ & $\mathrm{Al}$ & $\mathrm{O}$ & $\mathrm{C}$ & $\mathrm{Cu}$ \\
\hline A & $71.4 \pm 1.0$ & $1.5 \pm 0.1$ & $9.4 \pm 0.3$ & $17.7 \pm 1.3$ & 0.0 \\
Cu-A & $85.0 \pm 5.4$ & $0.9 \pm 0.1$ & $5.9 \pm 5.6$ & $8.0 \pm 5.3$ & $0.2 \pm 0.5$ \\
NA-A & $98.1 \pm 1.1$ & $0.5 \pm 0.2$ & $4.7 \pm 0.7$ & $5.6 \pm 0.9$ & 0.0 \\
Cu-NA-A & $80.6 \pm 12.5$ & $0.1 \pm 0.1$ & $1.7 \pm 1.0$ & $17.9 \pm 13.0$ & $0.5 \pm 0.5$ \\
\hline
\end{tabular}

Table 3: XPS analysis (atomic\%)

\begin{tabular}{lrrllll} 
Sample & Si $2 p$ & Al $2 p$ & O 1s & C 1s & N 1s & Cu 2p \\
\hline A & 2.03 & 17.70 & 27.4 & 52.85 & 0.0 & 0.0 \\
Cu-A & 14.84 & 7.26 & 16.8 & 58.37 & 1.05 & 1.68 \\
NA-A & 4.79 & 19.27 & 44.62 & 30.35 & 0.97 & 0.0 \\
Cu-NA-A & 11.42 & 9.21 & 21.12 & 52.9 & 2.5 & 2.86 \\
\hline
\end{tabular}



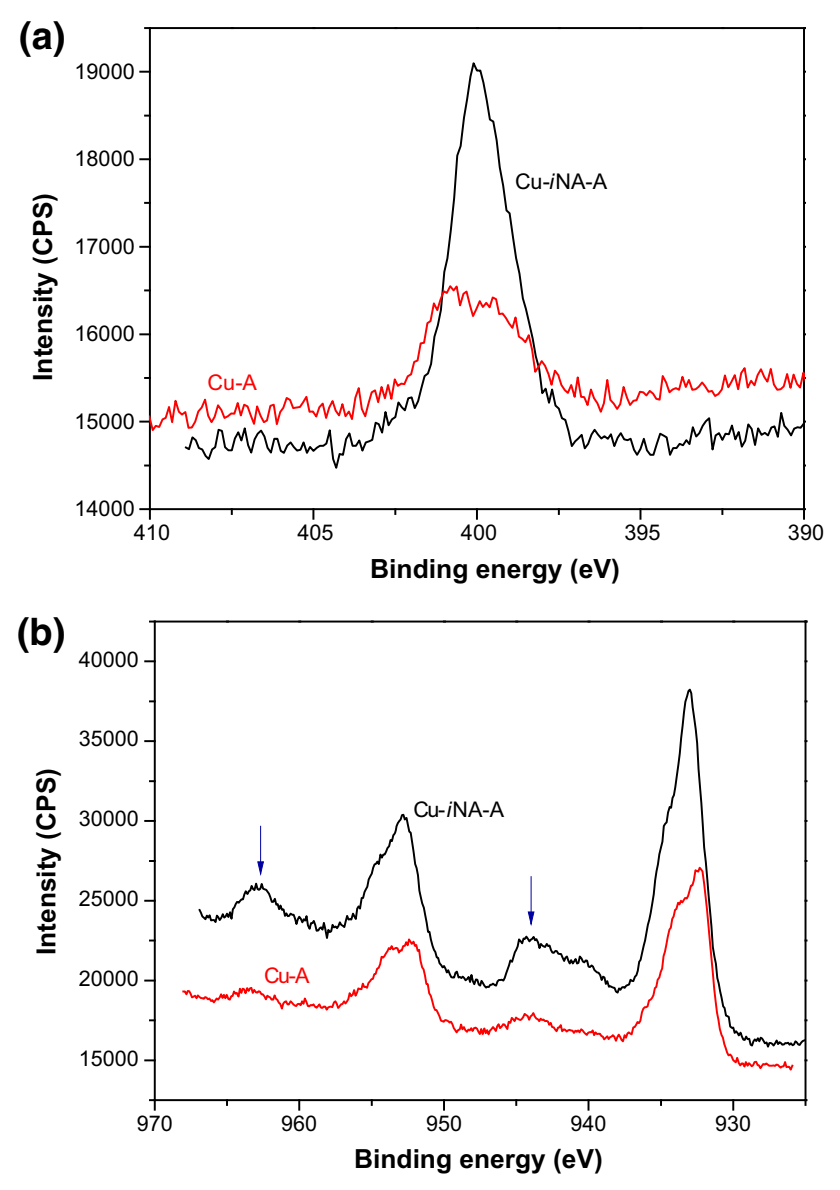

Fig. 8: High-resolution XPS spectra of (a) N 1s and (b) Cu $2 p$. The presence of smaller shake-up peaks in (b) is indicated
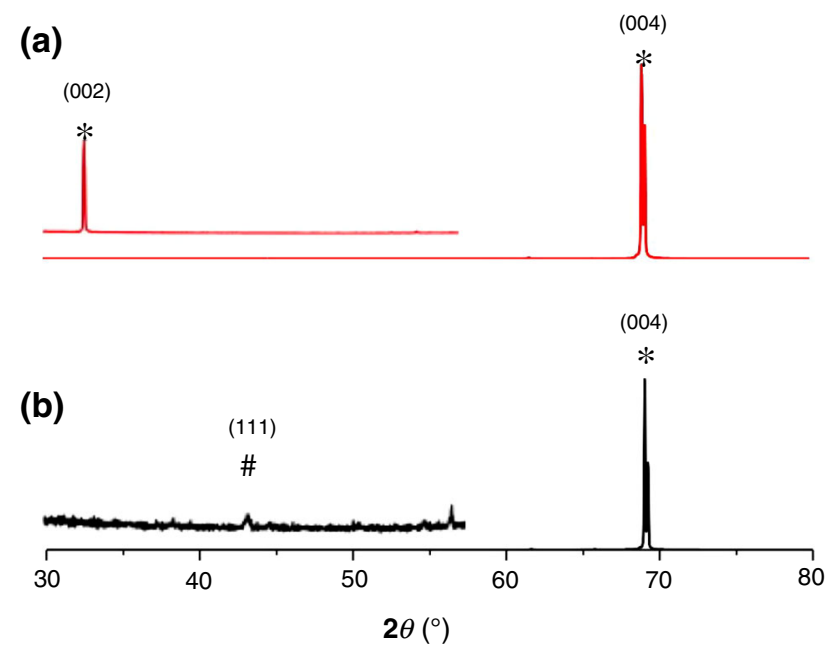

Fig. 9: XRD patterns of hydrazine-activated Cu ELD on (a) unfunctionalized alumina $(A)$ and (b) isonicotinic acidfunctionalized alumina (iNA-A). Si (COD 9011056)- and $\mathrm{Cu}$ (COD 7101264)-related signals are indicated with * and \# symbols, respectively. Peaks not identified are related with the incident spectra
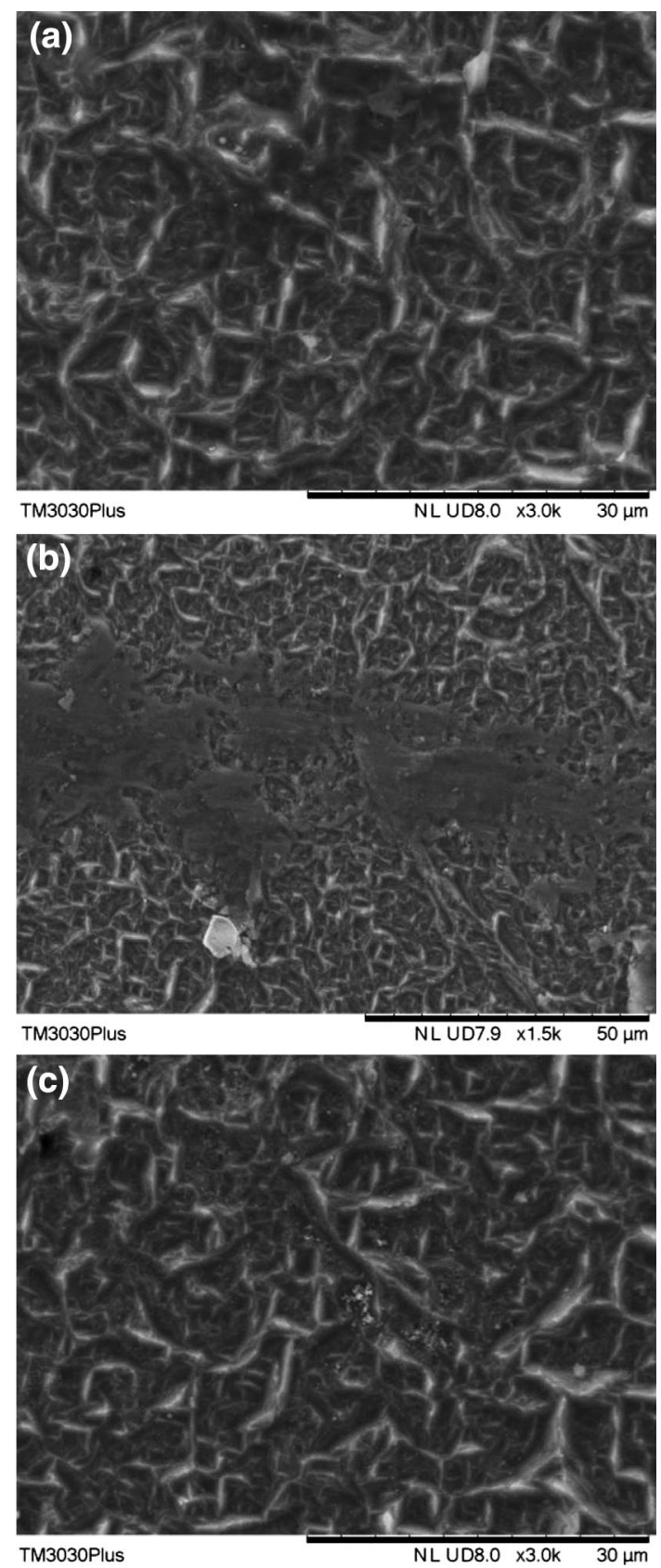

Fig. 10: SEM micrograph of (a) the surface of hydrazineactivated $\mathrm{Cu}$ ELD on an iNA-functionalized alumina wafer, (b) after being scratched with a glass cutter, and (c) after being subjected to a Scotch Tape test

tent with metallic $\mathrm{Cu}$ is observed $\left(2 \theta=43.2^{\circ}\right)$, see Fig. $9 \mathrm{~b}$. The confirmation of $\mathrm{Cu}^{0}$ suggests that the $\mathrm{Cu}(\mathrm{II})$ satellites seen in the XPS are due to surface oxidation of the nanoparticles. ${ }^{38}$

The $\mathrm{Cu}$ coating was found to be highly adhesive to the substrate. An area on the surface of hydrazineactivated $\mathrm{Cu}$ ELD on an $i \mathrm{NA}$-functionalized alumina wafer was scratched with a glass cutter. As can be seen 

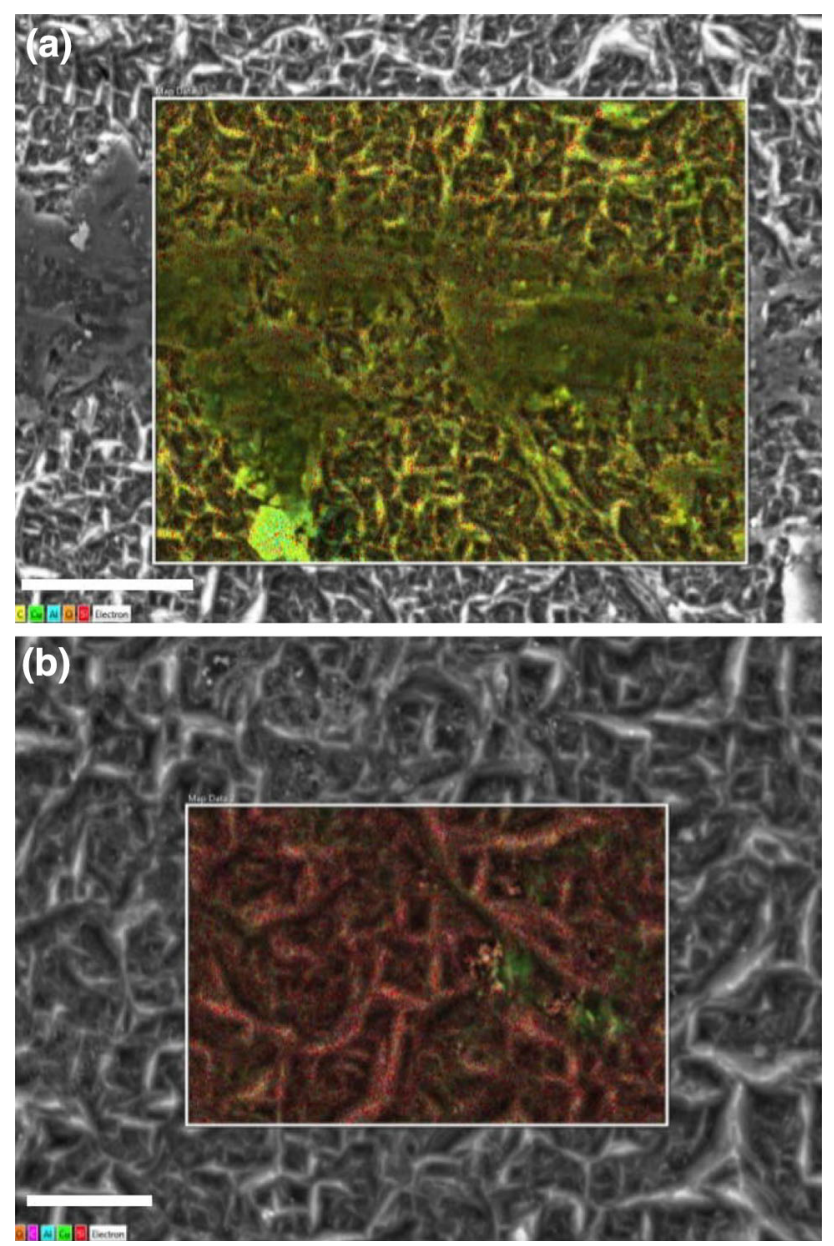

Fig. 11: Cu EDX mapping of the surface of hydrazineactivated $\mathrm{Cu}$ ELD on an iNA-functionalized alumina wafer (a) after being scratched with a glass cutter and (b) after being subjected to a Scotch Tape test. Scale bars are 25 and $10 \mu \mathrm{m}$, respectively

in the SEM micrographs of Figs. 10a and 10b, the scratch has changed the surface topography of the sample; however, EDX analysis of the surface after scratching (Fig. 11a) showed no variation in composition. This suggests that the surface of the $\mathrm{Cu}$ film is scratched as would be expected by the relative hardness of the diamond tip versus the metal, but that the film was not removed from the surface. In addition, a different area was subjected to a Scotch Tape test to probe the durability of the surface. As can be seen in Figs. 10c and 11b, there appears to be no effect on the adhesion of the film.

The water contact angles (CA) of the various functionalized and plated alumina wafers are shown in Table 4. The water CA of the Cu ELD on pristine alumina is not significantly different from the pristine alumina, while the isonicotinic acid-functionalized wafer endows the surface with a slightly higher hydrophilicity. This is consistent with previous dual functionality on alumina surfaces. ${ }^{27,28}$ On plating with
Table 4: Advancing contact angle $\left({ }^{\circ}\right)$

Sample

Contact angle $\left(^{\circ}\right)$

A

Cu-A

$96 \pm 2$

$94 \pm 3$

NA-A

$80 \pm 2$

CU-INA-A

$119.9 \pm 0.8$

copper, this surface is rendered more hydrophobic consistent with being coated by a metallic layer. ${ }^{39}$

\section{Conclusions}

In summary, the use of an isonicotinate self-assembled monolayer (SAM) is effective at promoting the heterogenous nucleation of $\mathrm{Cu}^{0}$ films on the surface. The high stability of the isonicotinate's pyridine Lewis base interaction with $\mathrm{Cu}^{2+}$ ensures the coordination. ${ }^{22}$ Based on analogy with other $\mathrm{Cu}^{2+}$ complexes with pyridine-type ligands, ${ }^{40,41}$ immobilization with isonicotinic acid ligands will reduce the reduction potential resulting in the preferential reduction of the surfacebound $\mathrm{Cu}^{2+}$ to $\mathrm{Cu}^{0}$. This already-deposited copper can then act as a catalyst for the deposition of further $\mathrm{Cu}^{2+}$ ions from the solution, allowing the deposition to proceed in an autocatalytic manner.

Acknowledgments The authors gratefully acknowledge the financial support provided by the Sêr Cymru National Research Network in Advanced Engineering and Materials, the Office of Naval Research (N00014-15-2717), and the Robert A. Welch Foundation (C-0002). ARB acknowledges the financial support provided by the Welsh Government Sêr Cymru Chair Programme.

Open Access This article is distributed under the terms of the Creative Commons Attribution 4.0 International License (http://creativecommons.org/licenses/by/4.0/), which permits unrestricted use, distribution, and reproduction in any medium, provided you give appropriate credit to the original author(s) and the source, provide a link to the Creative Commons license, and indicate if changes were made.

\section{References}

1. Osaka, T, Takano, N, "Microfabrication of Electro- and Electroless-Deposition and Its Application in the Electronic Field." Surf. Coat. Technol., 169-170 1-7 (2003)

2. Osaka, T, "Creation of Highly Functional Thin Films using Electrochemical Nanotechnology." Chem. Rec., 4 346-362 (2004)

3. Jankiewicz, BJ, Jamiola, D, Choma, J, Jaroniec, M, "SilicaMetal Core-Shell Nanostructures." Adv. Colloid Interfac., 170 28-47 (2012) 
4. Subramaniam, C, Yamada, T, Kobashi, K, Sekiguchi, A, Futaba, DN, Yumura, M, Hata, K, "One Hundred Fold Increase in Current Carrying Capacity in a Carbon Nanotube-Copper Composite." Nature Comm., 42202 (2013)

5. Koo, HC, Saha, R, Kohl, PA, "Copper Electroless Bonding of Dome-Shaped Pillars for Chip-to-Package Interconnect." J. Electrochem. Soc., 158 D698-D703 (2011)

6. Cho, SK, Lim, T, Lee, HK, Kim, JJ, "A Study on Seed Damage in Plating Electrolyte and Its Repairing in $\mathrm{Cu}$ Damascene Metallization." J. Electrochem. Soc., 157 D187D192 (2010)

7. Lu, Y, Meng, X, Yi, G, Jia, J, "In Situ Growth of CuS Thin Films on Functionalized Self-Assembled Monolayers using Chemical Bath Deposition." J. Colloid Interf. Sci., 356 726733 (2011)

8. Malki, M, Rozenblat-Raz, A, Duhin, A, Inberg, A, Horvitz, D, Shacham-Diamand, Y, "Thin Electroless Co(W, P) Film Growth on Titanium-Nitride Layer Modified by Self-Assembled Monolayer." Surf. Coat. Tech., 252 1-7 (2014)

9. Jie, Y, Fan, H, Niskala, JR, You, W, "Growth of Nickel Nanoparticles on an Organic Self-Assembled Monolayer Template by Means of Electroless Plating." Colloid. Surface. A, 434 194-199 (2013)

10. Radoeva, M, Monev, M, Ivanov, IT, Georgiev, GS, Radoev, B, "Adhesion Improvement of Electroless Copper Coatings by Polymer Additives." Colloid. Surface A, 460 441-447 (2014)

11. Mondin, G, Wisser, FM, Leifert, A, Mohamed-Noriega, N, Grothe, J, Dörfler, S, Kaskel, S, "Metal Deposition by Electroless Plating on Polydopamine Functionalized Microand Nanoparticles." J. Colloid Interf. Sci., 411 187-193 (2013)

12. Mondin, G, Lohe, MR, Wisser, FM, Grothe, J, MohamedNoriega, N, Leifert, A, Dörfler, S, Bachmatiuk, A, Rümmel, MH, Kaskel, S, "Electroless Copper Deposition on (3Mercaptopropyl)triethoxysilane-Coated Silica and Alumina Nanoparticles." Electrochim. Acta, 114 521-526 (2013)

13. Tabakovic, I, Riemer, S, Sun, M, "Self-Assembled Monolayer of 3-N,N-Dimethylaminodithiocarbamoyl-1-Propanesulfonic Acid (DPS) used in Electrodeposition of Copper.' $J$. Electrochem. Soc., 160 D3197-D3205 (2013)

14. Leussing, DL, Hansen, RC, “The Copper(II)-Pyridine Complexes and their Reaction with Hydroxide Ions." J. Am. Chem. Soc., 79 4270-4273 (1957)

15. Haynes, JS, Rettig, SJ, Sams, JR, Trotter, J, Thompson, RC, "Pyrazine and Pyridine Complexes of Copper(II) Trifluoromethanesulfonate. Crystal Structure of Tetrakis(pyridine) bis(trifluoromethanesulfonato-O)copper(II) and Magnetic Exchange in (Pyrazine)bis(trifluoromethanesulfonato-O)copper(II)." Inorg. Chem., 27 1237-1241 (1988)

16. Allan, JR, Brown, DH, Nuttall, RH, Sharp, DWA, "Pyridine Complexes of Iron(II), Copper(II), Zinc(II), and Cadmium(II) Halides." J. Chem. Soc. A, 1031-1034 (1966)

17. Otieno, T, Hutchison, AR, Krepps, MK, Atwood, DA, "Synthesis and Spectral and Thermal Properties of PyrazineBridged Coordination Polymers of Copper(II) Nitrate: An Experiment for Advanced Undergraduates." J. Chem. Educ., 79 1355-1357 (2002)

18. Allen, JJ, Barron, AR, "Molecular Structure of $\left[\mathrm{Cu}_{2}(\mathrm{MeCN})_{2}\right.$ $\left.(\mu \text {-tpy })_{2}\right]\left[\mathrm{BPh}_{4}\right]_{2}$ : A Helical Di-Cuprous Terpyridine Complex." J. Chem. Crystallogr., 38 879-882 (2008)

19. Allen, JJ, Barron, AR, "Unusual Co-Crystallization of Both Monomeric and Dimeric Forms of $\mathrm{Cu}[\mathrm{PhN}$ (py)(quin) $] \mathrm{Cl}_{2}$." J. Chem. Crystallogr., 41 654-663 (2011)

20. Allen, JJ, Hamilton, CE, Barron, AR, "Molecular Structures of $\mathrm{RN}(\mathrm{H}) \mathrm{Py}\left(\mathrm{R}=2,4,6-\mathrm{Me}_{3} \mathrm{C}_{6} \mathrm{H}_{2}, 2,6-\mathrm{Et}_{2} \mathrm{C}_{6} \mathrm{H}_{3}, \mathrm{Ph}_{3} \mathrm{C}\right)$ and the Copper Complex $\left[\mathrm{Cu}\left\{\left(2,4,6-\mathrm{Me}_{3} \mathrm{C}_{6} \mathrm{H}_{2}\right) \mathrm{N}(\mathrm{H}) \mathrm{Py}_{2}\right] \mathrm{BF}_{4} . "\right.$ J. Chem. Cryst., 39 573-580 (2009)

21. Allen, JJ, Hamilton, CE, Barron, AR, "Synthesis and Structural Characterization of $\left(2,6-{ }^{\mathrm{i}} \mathrm{Pr}_{2} \mathrm{C}_{6} \mathrm{H}_{3}\right) \mathrm{N}$ (quin) $)_{2}$ and $\left[\mathrm{Cu}\left\{\left(2,6-{ }^{\mathrm{i}} \mathrm{Pr}_{2} \mathrm{C}_{6} \mathrm{H}_{3}\right) \mathrm{N}(\mathrm{quin})_{2}\right\}_{2}\right] \mathrm{BF}_{4}$." J. Chem. Cryst., 2 130$136(2010)$

22. Gowenlock, CE, McGettrick, JD, McNaughter, PD, O'Brien, P, Dunnill, CW, Barron, AR, “Copper-Complexed Isonicotinic Acid Functionalized Aluminum Oxide Nanoparticles." Main Group Chem., 15 1-15 (2016)

23. Hamilton, CE, Ogrin, D, McJilton, L, Moore, VC, Anderson, R, Smalley, RE, Barron, AR, "Functionalization of SWNTs to Facilitate the Coordination of Metal Ions, Compounds and Clusters." Dalton Trans., 37 2937-2944 (2008)

24. Landry, CC, Pappè, N, Mason, MR, Apblett, AW, Tyler, AN, MacInnes, AN, Barron, AR, "From Minerals to Materials: Synthesis of Alumoxanes from the Reaction of Boehmite with Carboxylic Acids." J. Mater. Chem., 5 331341 (1995)

25. Koide, Y, Barron, AR, " $\left[\mathrm{Al}_{5}\left({ }^{\mathrm{t}} \mathrm{Bu}\right)_{5}\left(\mu_{3}-\mathrm{O}\right)_{2}\left(\mu_{3}-\mathrm{OH}\right)_{3}(\mu-\mathrm{OH})_{2}\right.$ $\left.\left(\mu-\mathrm{O}_{2} \mathrm{CPh}\right)_{2}\right]$ : A Model for the Interaction of Carboxylic Acids with Boehmite." Organometallics, 14 4026-4029 (1995)

26. Bethley, CE, Aitken, CL, Koide, Y, Harlan, CJ, Bott, SG, Barron, AR, "Structural Characterization of Dialkylaluminum Carboxylates: Models for Carboxylate Alumoxanes." Organometallics, 16 329-341 (1997)

27. Alexander, S, Morrow, L, Lord, AM, Dunnill, CW, Barron, AR, "pH-Responsive Octylamine Coupling Modification of Carboxylated Aluminium Oxide surfaces." J. Mater. Chem. A, 3 10052-10059 (2015)

28. Vogelson, CT, Keys, A, Edwards, CL, Barron, AR, "Molecular Coupling Layers Formed by Reactions of Epoxy Resins with Self-Assembled Carboxylate Monolayers Grown on the Native Oxide of Aluminum." J. Mater. Chem., 13 291-296 (2003)

29. Ogura, T, Malcomson, M, Fernando, Q, "Mechanism of Copper Deposition in Electroless Plating." Langmuir, 6 1709-1710 (1990)

30. Biner, H, Sellman, DZ, "X-ray Photoelectron Studies of Pentacarbonyl Chromium and Tungsten Complexes with Nitrogen Ligands." Naturforsch, 33b 173-179 (1978)

31. Barber, M, Connor, JA, Guest, MF, Hillier, IH, Schwarz, M, Stacey, M, "Bonding in Some Donor-Acceptor Complexes Involving Boron-Trifluoride-Study by Means of ESCA and Molecular Orbital Calculations." J. Chem. Soc., Faraday Trans. II, 69 551-558 (1973)

32. Lindberg, BJ, Hedman, J, "Molecular Spectroscopy by Means of ESCA 6 Group Shifts for N, P and As Compounds." Chem. Scr., 7 155-166 (1975)

33. Camalli, M, Caruso, F, Mattogno, G, Rivarola, E, "Adducts of Tin(IV) and Organotin(IV) Derivatives with 2,2'-Azopyridine. 2. Crystal and Molecular Structure of SnMe2Br2AZP and Further Mossbauer and Photoelectronic Spectroscopic Studies." Inorg. Chim. Acta, 170 225-231 (1990)

34. Yoshida, T, “An X-ray Photoelectron Spectroscopic Study of Several Ligands in Coordination Compounds." Bull. Chem. Soc. Jpn., 53 1327-1330 (1980)

35. Kawai, J, Tsuboyama, S, Ishizu, K, Miyamura, K, Saburi, M, "Ligand Determination of a Copper Complex by Cu 2P X-ray Photoelectron Spectroscopy." Anal. Sci., 10 853-857 (1994)

36. Zaumseil, P, "High-Resolution Characterization of the Forbidden Si 200 and Si 222 Reflections." J. Appl. Crystallogr., 48 (2) 528-532 (2015)

37. Lam, YC, Zheng, HY, Tjeung, RT, Chen, X, "Seeing the Invisible Laser Markings.” J. Phys. D: Appl. Phys., 42042004 (2009) 
38. Brege, JJ, Hamilton, CE, Crouse, CA, Barron, AR, "UltraSmall Copper Nanoparticles from a Hydrophobically Immobilized Surfactant Template." Nano Lett., 9 2239-2242 (2009)

39. Tao, YT, "Structural Comparison of Self-Assembled Monolayers of n-Alkanoic Acids on the Surfaces of Silver, Copper, and Aluminum."' J. Am. Chem. Soc., 115 4350-4358 (1993)

40. Lincoln, KM, Offutt, ME, Hayden, TD, Saunders, RE, Green, KN, "Structural, Spectral, and Electrochemical Properties of Nickel(II), Copper(II), and Zinc(II) Com- plexes Containing 12-Membered Pyridine- and PyridolBased Tetra-aza Macrocycles." Inorg. Chem., 53 1406-1416 (2014)

41. Rawat, SP, Choudhary, M, "Synthesis, Spectroscopic, and Electrochemical Studies on Some New Copper(II) Complexes Containing 2-[(Z)-Phenyl (Pyridine-2-yl) Methylidene] AminoBenzenethiol and Monodentate Ligands." Int. J. Inorg. Chem., 2014618943 (2014) 